\title{
Preparation of Hollow Fiber Membrane Containing ZnO Nanoparticles to Remove Natural Organic Matter
}

\author{
${ }^{1}$ Abdullah Adnan Abdulkarim*, ${ }^{1}$ Yosra Mohammed Mahdi1, ${ }^{2}$ Haider Jasim Mohammed \\ ${ }^{1}$ Iraqi Corrosion Center/ Corporation of Research and Industrial Development - Iraq \\ ${ }^{2}$ Chemical and Petrochemical Research Center/ Corporation of Research and Industrial Development - Iraq
}

\section{Article information}

\section{Article history:}

Received: September, 11, 2021

Accepted: October, 20, 2021

Available online: October, 20, 2021

Keywords:

Zinc oxide,

Membrane,

Natural organic matter

*Corresponding Author:

Abdullah Adnan Abdulkarim

amuusm@gmail.com

DOI:

https://doi.org/10.53523/ijoirVol8I2ID78

\begin{abstract}
Polyethersulfone/zinc oxide mixed matrix hollow fiber membrane was fabricated using dry/wet phase inversion method. Zinc oxide nanoparticles (2 wt.\%) were dispersed in N,N-dimethylacetamide (DMAc) solvent in the present of polyvinylepyrrolidene. The dope solution speed and take up speed was similar with performing the spinning process at room temperature. The produced membranes were characterized using scanning electron microscope (SEM), atomic force microscope (AFM), and Fourier transform infrared (FTIR) analysis. Membrane performance was evaluated using pure water flux (PWF), relative flux ration (RFR), and total organic carbon (TOC) removal efficiency. From SEM analysis, it was found that the nanoparticles were well dispersed in the polymeric matrix. From AFM results, it was observed that the modified membrane has higher surface roughness. The PWF of the modified membrane was enhanced, while the RFR showed to increase due to rougher membrane surface. The NOM remaoval of $\mathrm{PES} / \mathrm{ZnO}$ membrane was higher than that of PES membrane and reached to $27 \%$ compared to only $16.9 \%$ for pristine PES.
\end{abstract}

\section{Introduction}

Among various pollutants present in river water is the natural organic matters (NOM) [1]. The presence of NOM in the treated water could react with chlorine to form disinfection by -products (DBPs) such as trihalomethanes (THMs) habacetic acids (HAAS). These compounds are harmful to human body due to their carcinogenic effects. Therefore, the removal of NOM from water has become a challenging research topic in improvement of water purification techniques [2].

Application of membrane technology in production of drinking water found wide acceptance in the recent decade [3]. For their easy fabrications and higher efficiency, the polymeric membranes are currently the most widely used membranes type for water treatment compared to inorganic membranes equivalents [4]. The selection of polymeric material is a critical issue in these types of membranes. To produce membrane with long term durability and has a good resistance to heat and chemicals, polyethersulfone (PES) could meet this requirement. PES membrane considered one of the most important membranes which are widely used due to wide temperature limits, typically temperature (75-125) ${ }^{\circ} \mathrm{C}$ can be used routinely, this would be advantage in fermentation and biotechnology. Also, 
PES can easily fabricate membrane in a wide variety of configurations and modules with good resistance to various types of chemicals such as chlorine, alphatic hydrocarbons, alcohols, and acids.

However, due to low hydrophilicity of PES membrane, membrane flux is low and its surface is prone to fouling in comparison to the more hydrophilic polymeric membrane [5]. The hydrated layer that formed on the membrane surface was able to alleviate the organic matter fouling [6-7]. It was also shown that adsorption of foulants on membrane surface shows to decrease when membrane surface is more hydrophilic [8-10]. Therefore, the hydrophilicity of the membrane could be considered the controlling factor during the preparation of polymeric membranes for water and waste water filtration process.

The polymeric membrane characteristics could be improved using different methods such as blending, chemical treatment, grafting, and coating. All these approach normally focused on improving membrane flux as well as its hydrophilicity [11]. Nanocomposite membranes was adapter to produce membrane structure (as well as surface) with high productivity, good rejection, and excellent fouling resistance [12-13].

Recently, the implementation of nanoparticles in membrane structure found wide acceptance by researchers for their small size and high surface area. Due to hydrophilic nature, low cost, antibacterial property, $\mathrm{ZnO}$ nanoparticles considered one of the most important materials for improving membrane hydrophilicity and might mitigate membrane fouling [14]. For instance, at relatively wide range of $\mathrm{ZnO}$-nanoparticles, Balta et al. [24] reported that the water permeability and the humic acid rejection were improved. While, Shen and co-workers [18] added $\mathrm{ZnO}$ nanoparticles in membrane matrix at relatively low loading ratio $(0.199-0.793 \mathrm{wt} \%)$. There was an excellent improvement in membrane permeability obtained at $0.398 \mathrm{wt} . \%$ of zinc oxide nanoparticles. Recently, Ahmed et al. [15] stated that the PES-ZnO-nanoparticles mixed matrix hollow fiber membrane was able to alleviate fouling during filtration of real river water.

In the present work, $\mathrm{ZnO}$ nanoparticles was blended with PES to improve the rejection of NOM. Polyvinylpyrrolidone was used to improve the dispersion of nanoparticles in the dope solution and fabricated using phase inversion method. In comparison with control membrane, the modified membrane was characterized using SEM, AFM, and FTIR analysis. In addition, the membrane performance was evaluated using RFR and NOM rejection.

\section{Experimental Procedure}

\subsection{Materials}

Polyethersulfone (PES Ultrason E6020P with Mw=58,000 g/mol) was provide from BASF. Polyetheneglycol and N,N-dimethylacetamide (DMAc) solvent, were purchased from Sigma Aldrich (USA). Zinc oxide nanoparticles (commercial grade), with particle size (10-30 nm; purity >99\%), was supplied from US Research Nanomaterials, Inc. (Houston, TX).

\subsection{Preparation of PES/ZnO Hollow Fiber Membranes}

Membrane dope solution was prepared mainly from PES polymer. ZnO nanoparticles at 2 wt. \% was dispersed in DMAc solvent. The mixtures were ultrasonicated for $10 \mathrm{~min}$ and stirred for $3 \mathrm{~h}$ at $600 \mathrm{rpm}$. Polyvinylepyrrolidene was added (4 wt.\%), and the stirring was continued for another $1 \mathrm{~h}$. PES polymer was added (17.25 wt.\%) and the solution remains $5 \mathrm{~h}$ under stirring at $500 \mathrm{rpm}$ with $60{ }^{\circ} \mathrm{C}$ of heating temperature. The modified membrane with $\mathrm{ZnO}$ was named HF-ZnO and the pristine PES membrane was named HF-C. Table (1) shows the spinning conditions used in the production of HF membrane.

The dope solutions were put in an ultrasonic bath for $3 \mathrm{~h}$ to remove bubbles that formed during the mixing. The HF membranes were synthesized via dry-wet spinning technique. The dope and bore solutions were extruded via a spinneret at a fixed flow rate (Table 1). Before entering the coagulation bath, there was an air gap equal to $7 \mathrm{~cm}$. To complete the phase inversion, the produced membranes were put in distilled water for 4 days. Finally, the 
membranes were immersed in glycerol solution (50 wt. \%) for one day and then dried in air at room temperature until complete drying.

Table (1). Spinning conditions of producing HF membranes.

\begin{tabular}{ll}
\hline Dope speed $(\mathrm{cm} / \mathrm{s})$ & 15.278 \\
Take up speed $(\mathrm{cm} / \mathrm{s})$ & 15.278 \\
Draw ratio & 1.0 \\
AG $(\mathrm{cm})$ & 12.5 \\
Bore fluid composition & Distilled water \\
Dope flow rate/bore flow rate & $3 / 1$ \\
External coagulant & Tap water \\
Coagulant temperature $\left({ }^{\circ} \mathrm{C}\right)$ & 25 \\
Spinneret internal /external diameter $(\mathrm{mm})$ & $0.5 / 1$ \\
\hline
\end{tabular}

\subsection{Hollow FiberModule Preparation}

Four fibers were adapted to cut into $28 \mathrm{~cm}$ length and then potted in the module holder. After one day, the samples were immersed in ethanol (for one hour) followed by DI water for one day. In which, the effective hollow fiber length was $24 \mathrm{~cm}$.

\subsection{Membrane Characterizations}

Morphologies of HF membrane were inspected by SEM. HITACHI Tabletop Microscope instrument (TM-3000Japan) operated at $15 \mathrm{kV}$ was used to characterize the membrane. Membrane samples were cut and mounted horizontally on double-sided carbon adhesive foil. To minimize the electrostatic charging, sputter coating was used (Quorum -SC7620) to coat the sample surface with a thin layer of gold under vacuum.

Atomic Force Microscope SPA400 SII Technology was used to evaluate the surface roughness of the membranes with scan size of $50 \mu \mathrm{m}$ x $50 \mu \mathrm{m}$. Roughness parameters include the mean roughness ( $\mathrm{Ra}$ ) and the mean difference in height between the highest peaks and five lowest valleys (Rz) were calculated by AFM software.

FTIR spectroscopy was used to inspect the surface chemistry of the membranes. FTIR spectra for the HF membrane and ZnO-nanoparticles were obtained using Perkin Elmer spectroscope (Perkin Elmer System FT-IR 2000, USA). The infrared spectra were scanned within the range $(4000-550 \mathrm{~cm}-1)$.

\subsection{Performance evaluation}

The pure water flux and rejection of pristine PES and PES modified membranes were calculated by using a crossflow filtration setup. The laboratory testing rig consists of feed tank, liquid pump, pressure gauge, cross-flow cell, and control valve. All the labrotary experiments were performed at an ambient temperature of $25{ }^{\circ} \mathrm{C}$. The $\mathrm{HF}$ module was assembled in the testing rig for pure water flux and NOM rejection. River water (RW) samples were taken at one site within the Tigris near Al-Nahrain University. The RW samples were kept for two days to complete settling, and then the supernatant was used directly in the experiment without any further modification.

To decrease the impact of compaction, the membrane was compressed at pressure of 2 bar for 1 hours. To calculate PWF of HF membrane, fresh DW was utilized in a feed tank and re-circulated for 2 hours. The filtration pressures of PWF as well as RW flux were selected to be 1.5 bar.

The permeate flux was calculated every $10 \mathrm{~s}$ based on weight differences with the aid of electronic balance which was connected to a data acquisition system (AND Super Hybrid Sensor, Model: Fx-3000i, A \& D Company, Limited) and was calculated by Eq. 5 .

$$
\mathrm{J}_{\mathrm{WF}}=\frac{\mathbf{V}}{\mathbf{A}_{\mathbf{m}} * \mathbf{t}}
$$


where JWF is the pure water flux $\left(\mathrm{L} / \mathrm{m}^{2} \mathrm{~h}\right), \mathrm{V}$ is the permeate volume (L), Am is the effective membrane surface area $(\mathrm{m} 2)$ and $\mathrm{t}$ is the measurement time $(\mathrm{h})$. Then, the river water was charged into $5 \mathrm{~L}$ feed tank with full circulation of retentate. The filtration of river water was performed for 3 hours. In order to evaluate the NOM rejection performance in term of TOC, Eq. 2 has been used:

$$
\text { Rejection }(\%)=\left(1-\frac{\text { TOC }_{\text {sample }}}{\text { TOC }_{\text {river }}}\right) \times 100
$$

where, empirical correlation has been used to calculate the TOC content [16] as in Eq. 3:

$$
\operatorname{TOC}\left(\frac{m g}{L}\right)=(65.5 \times U V)-0.15
$$

To evaluate the membrane fouling tendency, the relative flux reduction (RFR) has been calculated as follows:

$$
\operatorname{RF} R(\%)=\left(1-\frac{J_{R W}}{J_{W F}}\right) \times 100
$$

where RFR is the relative flux reduction (\%), JRW is the river water permeate flux $\left(\mathrm{L} / \mathrm{m}^{2} \mathrm{~h}\right)$, and JWF is the initial $\operatorname{PWF}\left(\mathrm{L} / \mathrm{m}^{2} \mathrm{~h}\right)$.

\section{Results and Discussion}

\subsection{Membrane Characterization}

The SEM of cross sectional area and surface images of pristine and mixed matrix membranes are presented in Figure (1). From the surface images (Figure (1), it could be found that the dispersion of $\mathrm{ZnO}$ nanoparticles was good. However, aggregated nanoparticles were observed in a few locations on membrane surface. Regarding to cross sectional images, it was observed that both internal and external cross sections had a skin layers on both surfaces. In which, there was no significant difference in the thickness of skin layer of both membranes. In addition, the macrovoids were formed in both membranes. From SEM cross sectional image of the modified membrane, it was found that the $\mathrm{ZnO}$ nanoparticles were well dispersed along the cross section. 


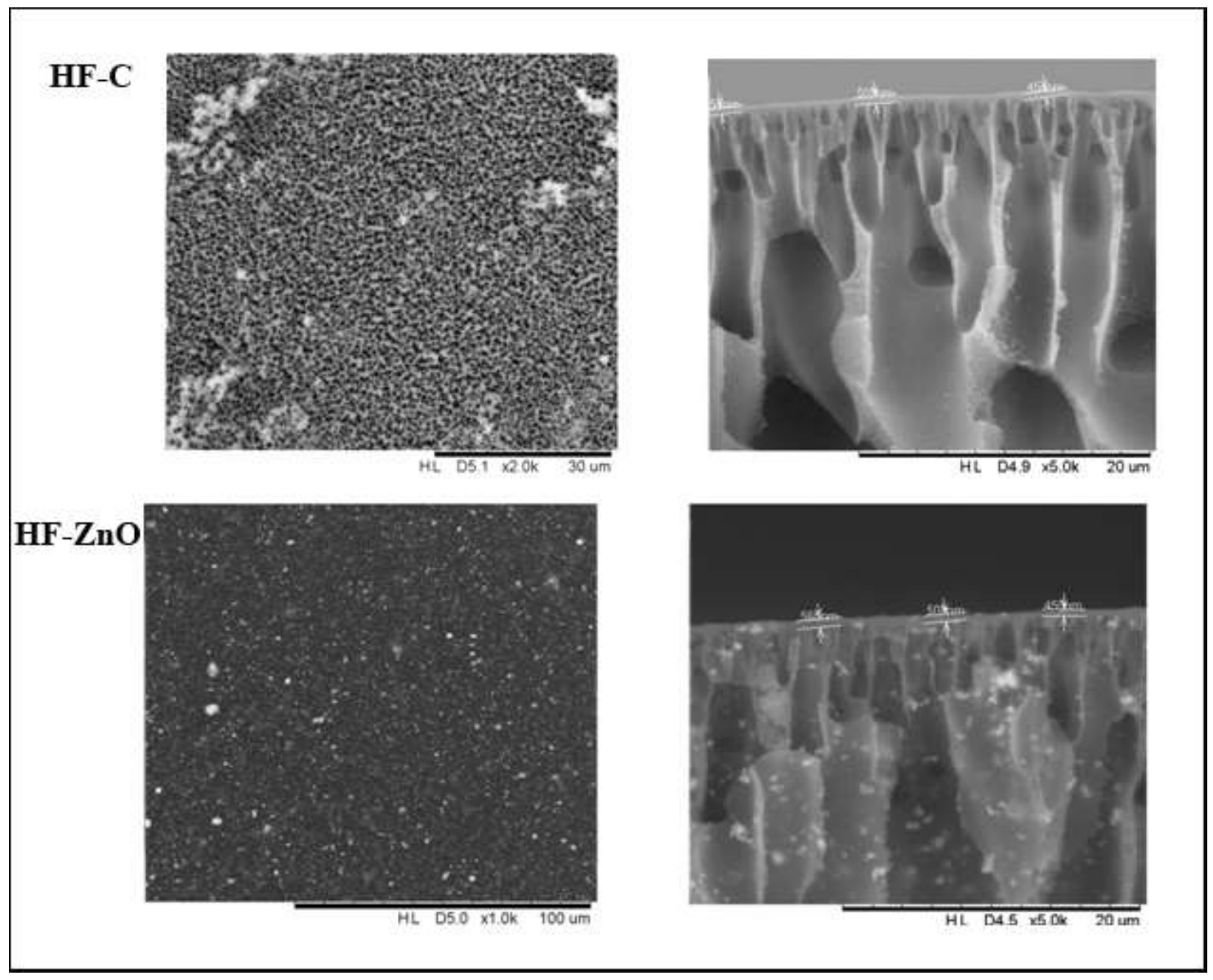

Figure (1). SEM images of membranes; the left images refer to surface SEM and the right images refer to cross sectional SEM of pristine (HF-C) and $\mathrm{ZnO}$ modified membrane (HF-ZnO).

The presence of zinc oxide in the nanoscale on membrane surface may play a significant role on the surface topography. To obtain more information about surface topography, AFM analysis could be beneficial in this case. Figure (2) shows the roughness images of the prepared membranes. The roughness parameters of the membranes were calculated as shown in Table 2. It could be clearly said that the ZnO/PES membrane surface is rougher than the pristine HF membrane surface. This phenomenon was also observed during the preparation of $\mathrm{ZnO}$-composite membranes [17]. In which, the membrane roughness parameters were increased as $\mathrm{ZnO}$ nanoparticles were incorporated in the PES matrix. In addition, the increase in surface roughness was observed when different nanoparticles were used to prepare mixed matrix membrane [18, 19]. Possible reason of the increased roughness upon the addition of nanoparticles is due to clusters' size [20]. 


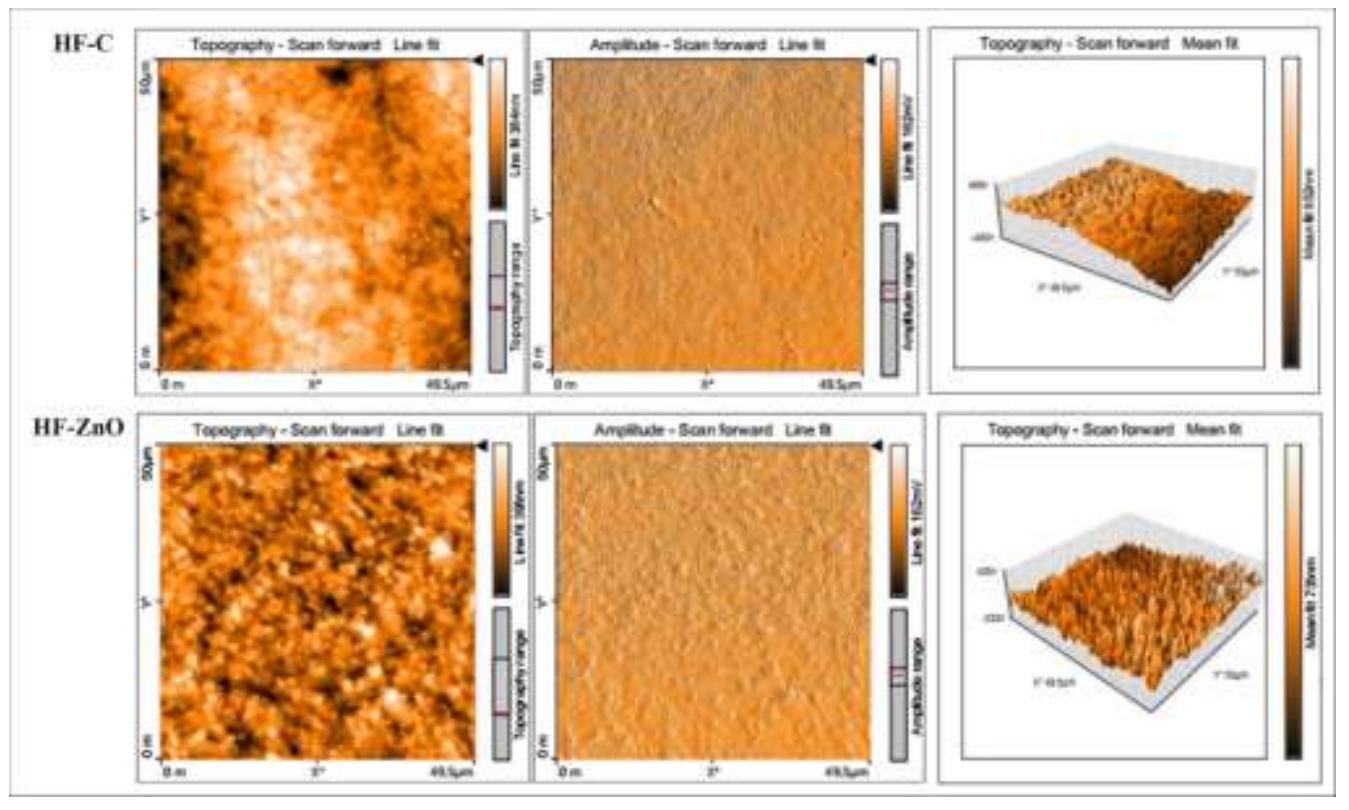

Figure (2). AFM images of the pristine (HF-C) and $\mathrm{ZnO}$ modified (HF- $\mathrm{ZnO})$ membranes.

Table (2). Roughness parameters of membranes.

\begin{tabular}{ccc}
\hline Membrane & $\begin{array}{c}\mathbf{R}_{\mathbf{a}} \\
(\mathbf{n m})\end{array}$ & $\begin{array}{c}\mathbf{R}_{\mathbf{z}} \\
(\mathbf{n m})\end{array}$ \\
\hline HF-C & 8.55 & 44.21 \\
HF-ZnO & 15.66 & 94.11 \\
\hline
\end{tabular}

The surface chemistry of the membrane could also play a significant role which might be altering the membrane performance. FTIR analysis has been used to identify the existence of certain chemical compounds or in another word the chemical bonds. The FTIR graph for PES membrane, PES-ZnO membrane, PVP, and ZnO -NPs were shown in Figure (3). PES membrane spectrum shows most of the peaks of PES molecular structure. It includes a benzene ring, an ether bond, and a sulfone structure [21]. There is a strong $\mathrm{C}=\mathrm{O}$ absorption peak that comes from the amide group of PVP located at $1652 \mathrm{~cm}^{-1}$, the $\mathrm{C}-\mathrm{N}$ group appeared at $1287 \mathrm{~cm}^{-1}$ and $\mathrm{C}-\mathrm{H}$ stretching and bending vibration frequencies can be seen between $2800-3000 \mathrm{~cm}^{-1}$ and $1423-1493 \mathrm{~cm}^{-1}$, respectively [22]. The $\mathrm{OH}$ stretching peak became wide and strong in the $3153 \mathrm{~cm}^{-1}-3687 \mathrm{~cm}^{-1}$ region. This indicated that hydrogen bonds were formed between $\mathrm{OH}$ groups of $\mathrm{ZnO}$ and oxygen atom in ether and sulfone groups of PES. It was found that there was a new absorption peak at $1664.4 \mathrm{~cm}^{-1}$. This new band is belonging to the carbonyl group of PVP. The present of this band in the membrane confirms that PVP is trapped in the PES structure. This will form an integral part with the polymeric structure, and could be the reason behid the increase in the membrane hydrophilicity. Vatasha and co-workers [23] prepared a PES/PVP membranes and also found a new absorption peak in the FTIR at $1677.5 \mathrm{~cm}^{-1}$. They attributed the formation of this peak to the entrapment a part of PVP inside the polymeric structure. 


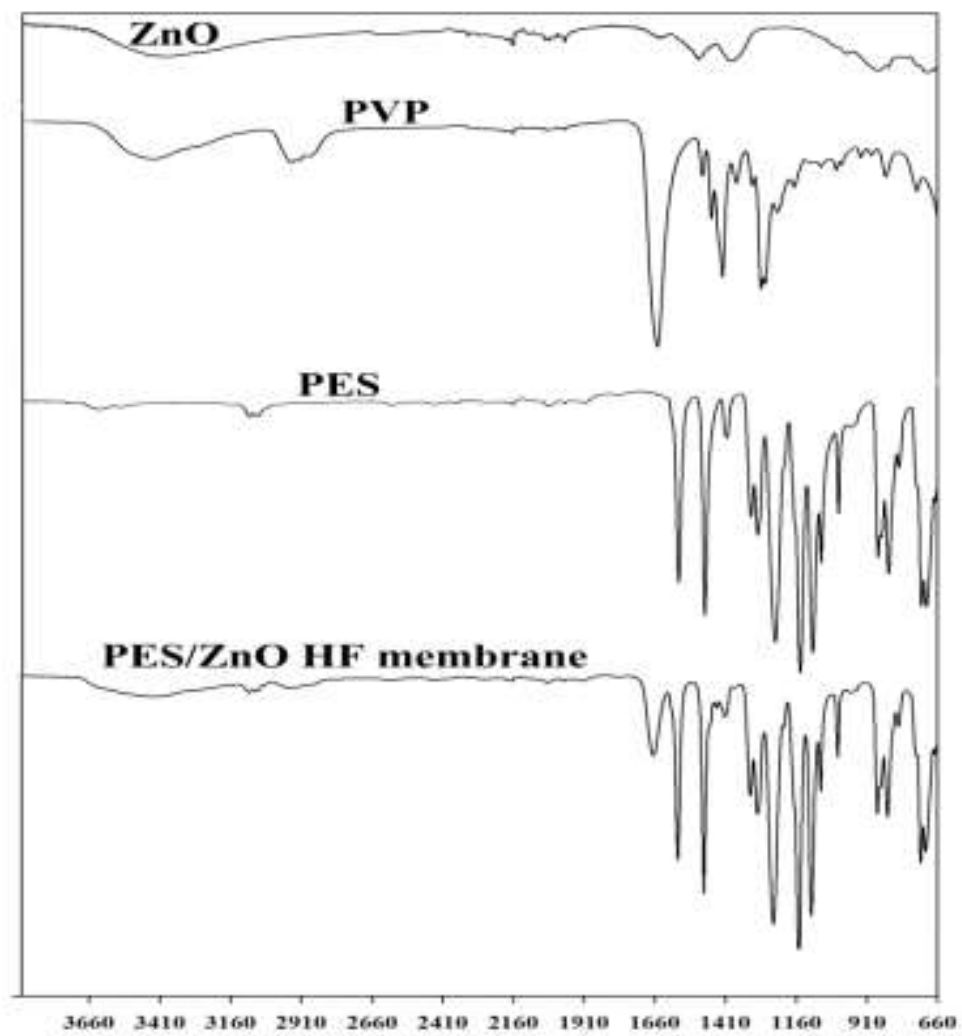

Figure (3). FTIR spectra of ZnO, PVP, PES, and PES/ZnO membrane.

\subsection{Performance Evaluations of PES/ZnO HF Membrane}

Membrane performance was evaluated using PWF, RFR and NOM rejection. The PWF of all membranes were shown in Figure (4). Due to limitations of pump that used in the experiments, there was a fluctuation in the flux of the distilled water as shown in Figure (4). The PWF of PES/ZnO HF membrane was improved when ZnO-NPs incorporated in PES structure as shown in Table (3). The improved PWF of the modified membrane could be attributed to the hydrophilic nature of $\mathrm{ZnO}$ and high surface area of nanoparticles.

However, the nanoparticles loading is a critical issue in which, the increase of $\mathrm{ZnO}$ loading could affect negatively on PWF due to ZnO-NPs coalescing and subsequently decreased the surface area of these particles as reported elsewhere [11]. As indicated in the SEM analysis, there was no significant difference in the skin layer of both pristine and PES/ZnO membranes. As shown in the FTIR results, some of the PVP was trapped in the polymeric structure (due to present of both PVP and $\mathrm{ZnO}$ ) and this help in an increase in membrane hydrophilicty. Therefore, the improvement of PWF of modified membrane could be attributed to improved hydrophilicty. 


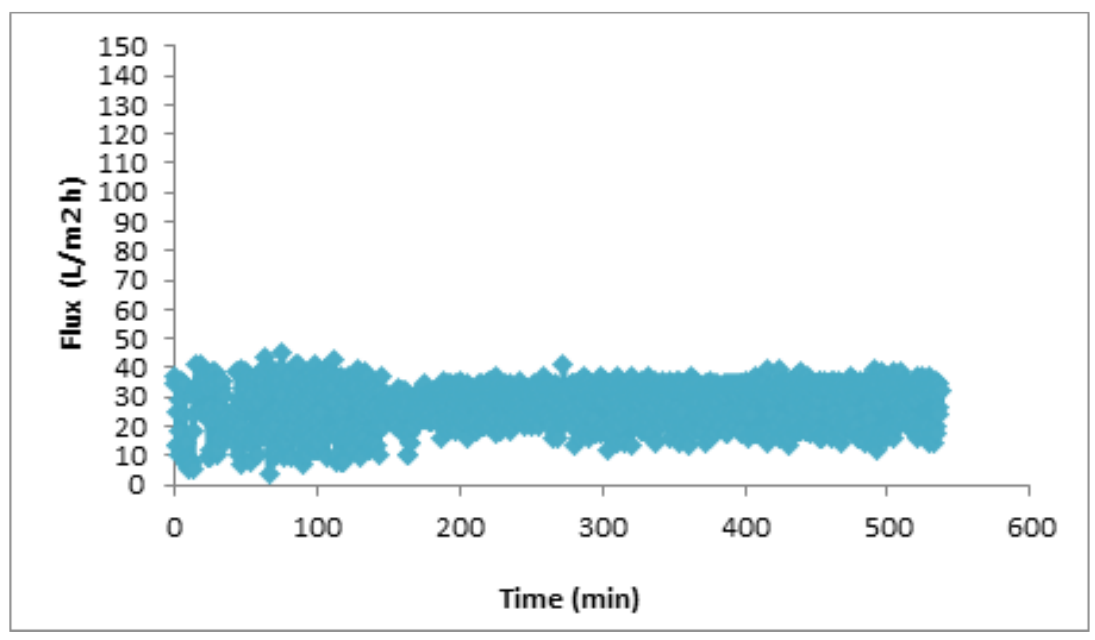

Figure (4). Pure water flux of $\mathrm{PES} / \mathrm{ZnO}$ with time.

Table (3). Pure water flux of membranes (measured at 1.5 bar).

\begin{tabular}{cccc}
\hline Membrane ID & $\begin{array}{c}\text { PWF } \\
\left(\mathbf{L}^{\mathbf{2}} \mathbf{h}\right)\end{array}$ & $\begin{array}{c}\text { PWF2 } \\
\left(\mathbf{L} / \mathbf{m}^{\mathbf{2}} \mathbf{h}\right)\end{array}$ & $\begin{array}{c}\text { RFR } \\
\mathbf{( \% )}\end{array}$ \\
\hline HF-C & 20.1 & 17.8 & 11.44 \\
HF-ZnO & 25.8 & 19.6 & 23.73 \\
\hline
\end{tabular}

The behaviors of PWF with time for the pristine and $\mathrm{ZnO}$ modified membranes were presented in Figure (5). The river water filtration started from $0 \mathrm{~min}$ and stopped at $200 \mathrm{~min}$. The tendency of membrane to foul was characterized by measuring the relative flux reduction (RFR). It is generally accepted that at a lower RFR, the membrane has lower tendency to foul. As shown in Table (3), the RFR obtained for HF-C and HF-ZnO are 11.44 and 23.73, respectively. The increased in the RFR of PES/ZnO membrane could be attributed to the increase in flux that lead to more accumulation of solute on membrane surface. As presented in the AFM analysis, the increased in roughness of the modified membrane could be the reason behind the increased RFR of this membrane.

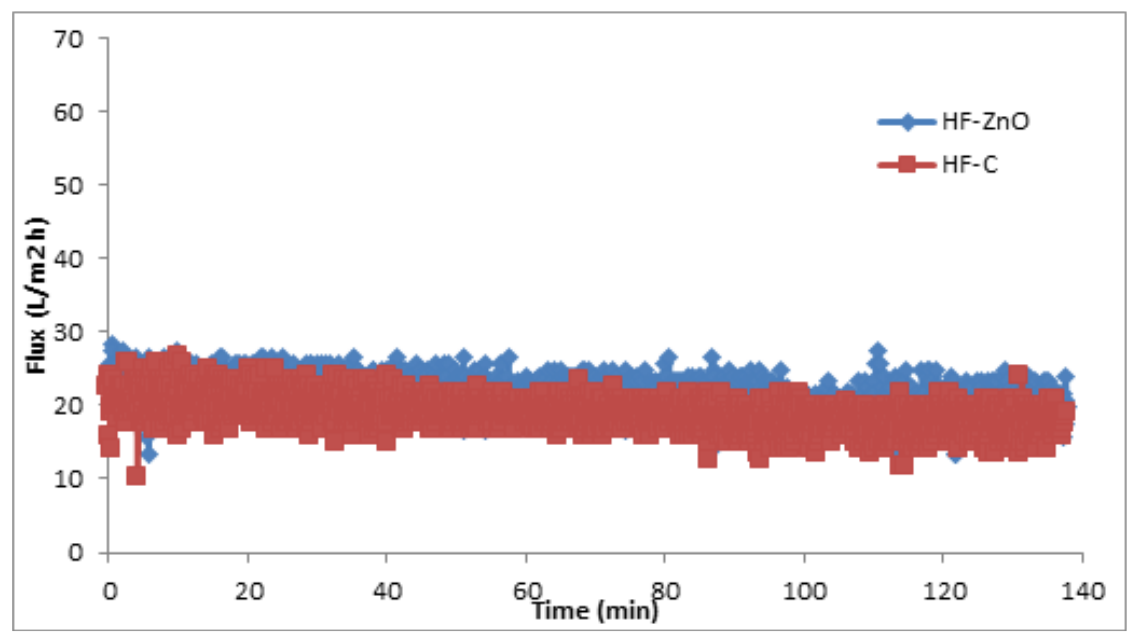

Figure (5). Fouling evaluation of HF-C and HF-ZnO membranes.

The evaluation of NOM rejection was achieved using the TOC evaluation. The TOC content was estimated using empirical equation by using UV-visible reading. The UV-vis, TOC, and the rejection of membrane results were tabulated in Table (4). 
Table (4). TOC and rejection results.

\begin{tabular}{cccc}
\hline & UV-river & TOC-new & Rejection \\
\hline River water & 0.15 & 9.675 & - \\
HF-C & 0.125 & 8.0375 & 16.92506 \\
HF-ZnO & 0.11 & 7.055 & 27.0801 \\
\hline
\end{tabular}

It was found that the NOM rejection of $\mathrm{ZnO}$ modified membrane was higher than that of pristine PES membrane (Table 4). This improvement in the rejection performance could be attributed to $\mathrm{ZnO}$ nanoparticles. Similar finding was also claimed by Ahmed et al. [11] in which the reported TOC rejection for PES/ZnO HF membrane was 26.15 $\%$ compared with only $6.92 \%$ for the control PES membrane. It is generally accepted that the RW NOM contains hydrophilic, transphilic, and hydrophobic fractions [21]. The hydrophobic parts such as HA has a negative charge on its surface. It was found in various reports that the removal efficiency of pollutants from RW was mainly depends on membrane characteristics and RW fractionations [21-22].

The removal of the hydrophobic fraction of NOM (measured using UV254) could be improved by adapting a negative charge on membrane surface. The removal of other fractions (hydrophilic and transphilic) could be controlled by MWCO of the membrane. Zularisam and co-workers [22] studied two different polymeric membranes that vary in pore size. They found that the UV254 rejection of polysulfone membrane was higher than that of cellulose acetate membrane. This phenomenon was attributed to the repulsion between negative charge of the membrane surface and the hydrophobic fraction of NOM. Therefore, the improvement of NOM rejection was due to decrease in the pore size and increase in the negative charge of PES/ZnO membrane surface. Thus, it could be concluded that the addition of $\mathrm{ZnO}$ - nanoparticles to PES improved the NOM rejection.

\section{Conclusions}

$\mathrm{PES} / \mathrm{ZnO}$ hollow fiber membrane was fabricated using dry/wet spinning process. The following conclusions were drawn from this study:

1. $\mathrm{ZnO}$ nanoparticles were well dispersed in PES matrix.

2. Surface roughness of PES/ $\mathrm{ZnO}$ membrane was higher than that of PES membrane.

3. From the FTIR analysis, it was shown that the present of $\mathrm{ZnO}$ and trapped PVP were helped in producing more hydrophilic surface.

4. Upon the addition of $\mathrm{ZnO}$, the PWF was $25.8 \mathrm{~L} / \mathrm{m} 2 \mathrm{~h}$ compared to only $20.1 \mathrm{~L} / \mathrm{m} 2 \mathrm{~h}$ for pristine PES.

5. The RFR of PES/ZnO membrane was $23.73 \%$ compared with $11.44 \%$ for pristine PES. The increased fouling tendency of the modified membrane was attributed to the increased in both PWF and membrane roughness.

6. NOM rejection shows that the PES/ZnO membrane exhibited $27.08 \%$ compare to only $16.92 \%$ for pristine PES.

\section{References}

[1] V. Vatanpour, S. S. M. Khadem, A. Dehqan, M. A. Al-Naqshabandi, M. R. Ganjali, S. S. Hassani, M. R. Rashid, M. R. Saeb, and N. Dizge, "Efficient removal of dyes and proteins by nitrogen-doped porous graphene blended polyethersulfone nanocomposite membranes," Chemosphere, vol. 263, p. 127892, 2021.

[2] J. Zhou, Y. Xia, Y. Gong, W. Li, and Z. Li, "Efficient natural organic matter removal from water using nano$\mathrm{MgO}$ coupled with microfiltration membrane separation," Science of The Total Environment, vol. 711, p. $135120,2020$.

[3] S. Abdikheibari, L. F. Dumée, V. Jegatheesan, Z. Mustafa, P. Le-Clech, W. Lei, and K. Baskaran, "Natural organic matter removal and fouling resistance properties of a boron nitride nanosheet-functionalized thin film 
nanocomposite membrane and its impact on permeate chlorine demand," Journal of Water Process Engineering, vol. 34, p. 101160, 2020.

[4] L. Y. Ng, A. W. Mohammad, C. P. Leo, and N. Hilal, "Polymeric membranes incorporated with metal/metal oxide nanoparticles: a comprehensive review," Desalination, vol. 308, pp. 15-33, 2013.

[5] V. Vatanpour, Y. Mansourpanah, S. S. M. Khadem, S. Zinadini, N. Dizge, M. R. Ganjali, S. Mirsadeghi, M. Rezapour, M. R. Saeb, and H. Karimi-Male, "Nanostructured polyethersulfone nanocomposite membranes for dual protein and dye separation: Lower antifouling with lanthanum (III) vanadate nanosheets as a novel nanofiller," Polymer Testing, vol. 94, p. 107040, 2021.

[6] Y. H. Teow, A. L. Ahmad, J. K. Lim, and B. S. Ooi, "Preparation and characterization of PVDF/TiO2 mixed matrix membrane via in situ colloidal precipitation method," Desalination, vol. 295, pp. 61-69, 2012.

[7] A. Asatekin, S. Kang, M. Elimelech, and A. M. Mayes, "Anti-fouling ultrafiltration membranes containing polyacrylonitrile-graft-poly (ethylene oxide) comb copolymer additives," Journal of membrane science, vol. 298, pp. 136-146, 2007.

[8] S. Cowan and S. Ritchie, "Modified polyethersulfone (PES) ultrafiltration membranes for enhanced filtration of whey proteins," Separation Science and Technology, vol. 42, pp. 2405-2418, 2007.

[9] S. Zhao, W. Yan, M. Shi, Z. Wang, J. Wang, and S. Wang, "Improving permeability and antifouling performance of polyethersulfone ultrafiltration membrane by incorporation of ZnO-DMF dispersion containing nano-ZnO and polyvinylpyrrolidone," Journal of membrane science, pp. 105-116, 2015.

[10] E. Celik, H. Park, H. Choi, and H. Choi, "Carbon nanotube blended polyethersulfone membranes for fouling control in water treatment," Water Research, vol. 45, pp. 274-282, 2011.

[11] A. Ahmad, A. Abdulkarim, Z. M. Shafie, and B. Ooi, "Fouling evaluation of PES/ZnO mixed matrix hollow fiber membrane," Desalination, 2016.

[12] D. Rana and T. Matsuura, "Surface modifications for antifouling membranes," Chemical reviews, vol. 110, pp. 2448-2471, 2010.

[13] Y. Jafarzadeh, R. Yegani, and M. Sedaghat, "Preparation, characterization and fouling analysis of $\mathrm{ZnO}$ /polyethylene hybrid membranes for collagen separation," Chemical Engineering Research and Design, vol. 94, pp. 417-427, 2015.

[14] H. Rajabi, N. Ghaemi, S. S. Madaeni, P. Daraei, B. Astinchap, S. Zinadini, and S. H. Razavizadeh, "Nano$\mathrm{ZnO}$ embedded mixed matrix polyethersulfone (PES) membrane: Influence of nanofiller shape on characterization and fouling resistance," Applied Surface Science, vol. 349, pp. 66-77, 2015.

[15] A. Ahmad, A. Abdulkarim, B. Ooi, and S. Ismail, "Recent development in additives modifications of polyethersulfone membrane for flux enhancement," Chemical engineering journal, vol. 223, pp. 246-267, 2013.

[16] R. Albrektienè, M. Rimeika, E. Zalieckienè, V. Šaulys, and A. Zagorskis, "Determination of organic matter by UV absorption in the ground water," Journal of Environmental Engineering and Landscape Management, vol. 20, pp. 163-167, 2012.

[17] A. Ahmad, A. Abdulkarim, S. Ismail, and B. Ooi, "Preparation and characterisation of PES-ZnO mixed matrix membranes for humic acid removal," Desalination and Water Treatment, pp. 1-12, 2014.

[18] J.-M. Yeh, M.-Y. Yu, and S.-J. Liou, "Dehydration of water-alcohol mixtures by vapor permeation through PVA/clay nanocomposite membrane," Journal of Applied Polymer Science, vol. 89, pp. 3632-3638, 2003.

[19] M. Rezaei, A. F. Ismail, S. A. Hashemifard, G. Bakeri, and T. Matsuura, "Experimental study on the performance and long-term stability of PVDF/montmorillonite hollow fiber mixed matrix membranes for CO2 separation process," International Journal of Greenhouse Gas Control, vol. 26, pp. 147-157, 2014.

[20] A. Sotto, A. Rashed, R.-X. Zhang, A. Martínez, L. Braken, P. Luis, and B. Van der Bruggen, "Improved membrane structures for seawater desalination by studying the influence of sublayers," Desalination, vol. 287, pp. 317-325, 2012.

[21] Y. Ji-xiang, S. Wen-xin, Y. Shui-li, and L. Yan, "Influence of DOC on fouling of a PVDF ultrafiltration membrane modified by nano-sized alumina," Desalination, vol. 239, pp. 29-37, 2009.

[22] A. Zularisam, A. F. Ismail, M. Salim, M. Sakinah, and H. Ozaki, "The effects of natural organic matter (NOM) fractions on fouling characteristics and flux recovery of ultrafiltration membranes," Desalination, vol. 212, pp. 191-208, 2007.

[23] B. Vatsha, J. C. Ngila, and R. M. Moutloali, "Preparation of antifouling polyvinylpyrrolidone (PVP 40K) modified polyethersulfone (PES) ultrafiltration (UF) membrane for water purification," Physics and Chemistry of the Earth, Parts A/B/C, vol. 67-69, pp. 125-131, 2014. 